\title{
Recognizing states of psychological vulnerability to suicidal behavior: a Bayesian network of artificial intelligence applied to a clinical sample
}

\author{
Jorge Barros ${ }^{1}$, Susana Morales ${ }^{1,2^{*}}$, Arnol García ${ }^{3}$, Orietta Echávarri ${ }^{1,2}$, Ronit Fischman², Marta Szmulewicz ${ }^{1,2}$, \\ Claudia Moya ${ }^{4,2}$, Catalina Núñez ${ }^{1}$ and Alemka Tomicic ${ }^{2,5}$
}

\begin{abstract}
Background: This study aimed to determine conditional dependence relationships of variables that contribute to psychological vulnerability associated with suicide risk. A Bayesian network (BN) was developed and applied to establish conditional dependence relationships among variables for each individual subject studied. These conditional dependencies represented the different states that patients could experience in relation to suicidal behavior (SB). The clinical sample included 650 mental health patients with mood and anxiety symptomatology.

Results: Mainly indicated that variables within the Bayesian network are part of each patient's state of psychological vulnerability and have the potential to impact such states and that these variables coexist and are relatively stable over time. These results have enabled us to offer a tool to detect states of psychological vulnerability associated with suicide risk.

Conclusion: If we accept that suicidal behaviors (vulnerability, ideation, and suicidal attempts) exist in constant change and are unstable, we can investigate what individuals experience at specific moments to become better able to intervene in a timely manner to prevent such behaviors. Future testing of the tool developed in this study is needed, not only in specialized mental health environments but also in other environments with high rates of mental illness, such as primary healthcare facilities and educational institutions.
\end{abstract}

Keywords: Suicide, Mood disorders, Artificial intelligence, Bayesian models

\section{Background}

Decades of research have repeatedly demonstrated that our ability to correctly assess the risk of suicidal behavior $(\mathrm{SB})$ is very limited $[9,16,38,39]$. A recent systematic review using a meta-analysis of 44 studies conducted between 1945 and 2013 showed a rate of

\footnotetext{
* Correspondence: sus.mosi@gmail.com

'Psychiatry Department, School of Medicine, Pontificia Universidad Católica de Chile, La Reconquista 498, Las Condes, Santiago, Chile

${ }^{2}$ Millennium Institute for Research in Depression and Personality MIDAP Santiago, Chile

Full list of author information is available at the end of the article
}

$147 / 100,000$ inpatient suicides, which the authors described as "unacceptable mortality in psychiatric hospitals." The results suggested that the rate of inpatient suicides may have risen over recent decades [40].

While it is certainly difficult to anticipate suicidal behavior (SB) during hospitalization, it is equally difficult once a patient has been discharged. A meta-analysis of 100 studies of SB and ideation, which were chosen from a total of 11,449 studies originally selected, showed that the greatest risk of suicide occurred during the first 3 months after discharge. Such risk was estimated at a rate 
of 1132/100,000 during the first 3 months, which slowly declined depending on the follow-up period.

The risk decreased to 494/100,000 when follow-ups were between 1 and 5 years after discharge, to $366 / 100$, 000 for follow-ups between 5 and 10 years after discharge, and to 277/100,000 for follow-ups 10 years or more after discharge. The authors noted that studies using data collected after 1995 show much higher suicide rates [9].

Another meta-analysis titled "50 Years of Research on Risk Factors and Suicidal Ideation" [12] concluded that "the ability to predict suicide has not improved in 50 years of research" (p.191). For a better understanding of $\mathrm{SB}$, the authors suggested conducting follow-up studies, where findings should be combined in a complex and replicable way.

Our use of DM and AI tools is intended to complement the use of traditional statistics. This type of analysis adds utility when processing large volumes of data, which requires an understanding of complex phenomena. Such understanding is possible through observing unexpected relationships and conditional dependencies in the data and investigating beyond the hypotheses that may have been established a priori.

Other authors have used MD techniques to study the possible association of clinical and/or demographic variables with past or future suicidal behavior. This approach was used in several very relevant works carried out by different groups $[3,22]$. We take a different approach since we want to recognize which configuration of variables is most likely at the time of the risk of SB.

In fact, two studies published in 2017 that used machine learning techniques revealed the advantages of such techniques for studying SB ( [30]; C. G [39].). Overall, the evidence mentioned above has suggested that a paradigm shift is needed [15]. Such a shift can be achieved by studying populations in primary care facilities who are in states that precede SB [16]. Considering the fluctuating nature of $\mathrm{SB}$, efforts to explore the uniqueness of each factor related to its preceding psychological conditions may be challenging.

We recognize the need to consider the simultaneous presence of variables as well as the existence of new factors in SB research. Within the category of "new factors, " we include groups of variables that operate simultaneously. In other words, a new factor might constitute a configuration of variables that emerge at a particular time $[5,23,25]$. While there is still a lack of reliable tools to predict suicide, certain factors that are predominant when a person attempts to end his or her life can be established [36, 42]. Several researchers have studied mental states preceding SB by using different methodologies. Based on information provided by therapists, Hendin, Maltsberger, Haas, Szanto, and Rabinowicz
(2004) compared reports of the affective states of patients who attempted suicide to those of control participants. The researchers suggested that "despair" was the most prevalent emotional state in participants who attempted suicide.

Tucker et al. [35] proposed the diagnostic entity "acute suicidal affective disturbance" (ASAD) to describe a common clinical condition among those exhibiting SB that can be deemed independent from their overall diagnoses. ASAD has been validated with the ASADI-L diagnostic instrument, which, according to the researchers, should be prospectively evaluated in individuals as well as through family studies. Galynker et al. [13] recently used the Suicidal Crisis Inventory (SCI) to study SB in a group of inpatients for four to 8 weeks. This scale has 49 items exploring five traditional factors: entrapment, panic-dissociation, ruminative flooding, fear of dying, and emotional pain. Among these factors, SB is mostly plausible based on higher indices for entrapment. Methods that have been tested to assess SB are complementary. Each method can be used to identify risks for subgroups of individuals with SB. For instance, the ASADI-L particularly emphasizes risk assessment in patients with prior suicidal intents, and the SCI evaluates emotional states preceding $\mathrm{SB}$, as shown in the work carried out by Hendin.

We believe that several affective states may interact to place an individual in a state of vulnerability. Considering the complexity of the present task, we favored factor selection by means of a mathematical model. The predictive value of our model should be assessed in future studies by using a strategy similar to that used by Galynker et al. [13]. By focusing on the detailed study of clinical conditions that accompany SB, we also aimed to reveal the variables that can be modified to move patients away from a state characteristic of SB toward a state characteristic of individuals without SB. With this goal in mind, we used various data mining (DM) techniques, namely, support vector machine (SVM), decision tree (DT) and Bayesian network (BN), to specify unique relationships between variables contributing to the state of psychological vulnerability associated with SB.

Over the years, research has identified different risk factors for SB, among which psychiatric disorders, especially depressive disorders [43], and previous suicide attempts [4] have been deemed the most important. Along with depression, other mental disorders, such as schizophrenia, bipolar disorder, substance abuse disorder, eating disorder and borderline personality disorder, are highly present in individuals with suicidal behavior [43]. Likewise, alexithymia has been linked to an increased risk of suicide through the intensification of the propensity to develop depressive symptoms or the enhancement of psychological distress [10]. The literature 
has described a long list of risk factors in the social, family, biological and personality realms. Nevertheless, the purpose of this study is not to delve into the list of factors (see [43]) but to propose a way in which such risk factors can be analyzed with a novel technique to deepen our understanding of each factor's dynamic and individual presence.

We used the structure of the data from our first two DM experiments (SVM and DT) to explore the findings that emerged regarding the difference between protective and risk factors $[5,25]$. Subsequently, we delved deeper into the dependence relationships among the variables by using the Bayesian network technique [33]. This technique provided a perspective on the conditional dependence relationships among variables in individual cases. The findings of this in-depth study should be used to provide recommendations for clinical interventions.

We acknowledge that suicide risk is highly individual and represents a critical manifestation of particular configurations of common factors. In other words, this study sheds light on the specificity of the subjective experience of psychological suffering by examining unique configurations of variables that differed from those already identified in the literature. Such configurations were deemed to be multidimensional, with each variable representing specific weights and interacting within conditional dependence relationships $[19,41]$.

\section{Main purpose}

In light of the above, the purpose of this study was to deepen the understanding of the phenomenon of suicide through the study of psychological variables present in a clinical population that had presented suicidal ideation and suicidal behavior. We aimed to determine the relationships between variables and the existence of conditional dependency relationships ${ }^{1}$ beyond the preliminary hypotheses. The study will allow clinicians to have a tool that is applicable to the particularities of each patient in psychotherapeutic interventions that address both the weaknesses and strengths of patients.

The findings are presented in the results section below.

\section{Method}

The preliminary hypothesis on which the study is based suggests that the more dysfunctional clinical variables that are present, the greater the psychological vulnerability to suicidal behavior.

\footnotetext{
${ }^{1}$ Conditional dependency relationships: measures of the probability of an event occurring given that another event has (by assumption, presumption, assertion or evidence) occurred [14].
}

\section{Participants}

The data analyzed here were drawn from responses from a clinical sample of patients with mood and anxiety symptomatology. Sampling was consecutive and purposive based on the availability of participants. Participants were either ambulatory or hospitalized patients from three mental healthcare centers serving three socioeconomic strata (high, medium and low) in Greater Santiago, Chile.

\section{Inclusion criteria}

The study included female and male participants who were available to participate in the study, who were able to distinguish between fantasy and reality, and who were in an emotional and cognitive state that enabled them to answer the assessment questions. Patients consulting for addiction, eating disorders, psychotic disorders or cognitive disorders were not included to control for the diagnosis variable, but it was recognized that these pathologies can be strongly linked to suicide risk [11, 17, 29]. In addition, data from patients who chose not to participate or who later withdrew from the study were not included.

Participants were undergoing treatment as usual (TAU), which in the case of hospitalized patients consisted of crisis intervention with psychological, psychiatric, and occupational therapy approaches. For outpatients, treatment consisted of psychiatric and psychological approaches. This study was a cross-sectional evaluation of specific moments in participants' timelines.

Psychiatric diagnoses were made in collaboration with the treating teams according to the diagnostic criteria established in the Diagnostic and Statistical Manual of Mental Disorders, 4th Edition (DSM-IV-TR) [1].

\section{Prior findings}

Previous results from the same group of patients were used for the development of Bayesian networks [27]. SVM analysis provided variables that placed patients in either a risk or no risk condition. DT analyses showed possible configurations of combinations that could be located (depending on the route) in a state of risk or no risk. Such prior results were used to select relevant clinical and personality variables that either made individuals less likely to experience the psychological vulnerability associated with suicidal risk or placed them in such a state. These variables included psychological distress resulting in dysfunctionality, a dysfunctional experience, expression of aggression, factors that prevented suicidal behavior, destructive depressive experiences, and satisfaction with family functioning ([24], 2015; Morales, Echávarri, [5, 26, 34]).

The characteristics of the analyses included in this study are detailed below: 
- Support vector machine (SVM) model. ${ }^{2}$ This technique was used to define whether a group was either at risk or not at risk by using supervised learning models linked to learning algorithms that analyzed and recognized patterns. The model generated 22 variables that, depending on the circumstances in which they occurred, defined whether a person belonged within a suicide risk configuration [5].

- Decision tree (DT) model. ${ }^{3}$ This technique was used to process and analyze large quantities of explicative variables. Based on the lowest Gini index [7] and given an appropriate and a sufficient number of questions, it was possible to identify four decision trees and a trajectory of psychological variables, which created a state of vulnerability to suicidal behavior [25]. The progression of these analyses is detailed in the Results section below, where we mention our prior work $[5,25]$.

- Sociodemographic and clinical information. Several descriptive variables were assessed: demographic, social, clinical, diagnostic, reasons for seeking treatment, and a description of the participant's behavior or suicidal ideation, when applicable.

- In the present study, we further identified conditional relationships among variables using the graphical model technique [2], specifically the Bayesian network technique [33].

A probabilistic graphical model is defined as a collection of graphs representing conditional probabilities between different variables. The Bayesian network is a type of probabilistic graphical model in which a defining graph fulfills certain specific properties (acyclic and directed).

Selected graph theory concepts are defined below:

- Graph: A collection of nodes or vertices as well as a collection of arcs (or edges) in which each arc connects nodes and is visually represented with lines that join nodes.

\footnotetext{
${ }^{2}$ Support vector machine models: Supervised learning models associated with learning algorithms that analyze data used for regression and classification analysis. Starting with a set of training examples, each marked as belonging to one or the other of two categories, an SVM training algorithm builds a model that assigns new examples to one category or the other, hence resolving a nonprobabilistic binary linear classifier [6].

${ }^{3}$ Decision tree technique: A model of computation in which an algorithm is considered to be a sequence of branching operations based on comparisons of some quantities, the comparisons being assigned the unit computational cost. The branching operations are called "queries or tests". The algorithm may be considered a computation of a Boolean function where the input is a series of queries and the output is a final decision, in which every query is dependent on previous queries or tests [7].
}

- Directed graph: A graph where all the arcs are directed; that is, they have a starting node and an ending node and are represented by arrows on the arcs.

- Acyclic graph: A graph is acyclic if it is directed, and there are no sequences of arcs that start at one node and end at the same node. In other words, there is no "route" that leaves from and arrives at the same node.

- Node parent: Node A is considered a parent of node $B$ if there is a directed edge from A to B.

- Node children: Node $C$ is considered a child of node $\mathrm{B}$ if there is a directed edge from $\mathrm{B}$ to $\mathrm{C}$.

A Bayesian network consists of the following:

- A network structure represented by a directed acyclic graph (DAG) where there is a collection of nodes, in which each node represents a random variable, and each edge represents a dependency relationship or correlation between variables.

- A probability distribution of parameters that can be deconstructed in a local probability distribution based on arcs found in the graph.

- Codes for conditional dependence relationships among the variables in its graph, revealing joint probability distributions expressed as factorizations of local probabilities, in which joint probabilities of all the variables can be calculated as the products of the probabilities of all the variables given their parent values.

\section{Instruments}

We developed a psychological evaluation instrument [5] available both online and offline. The instrument includes 25 questions to be answered on a Likert scale, and the answers are analyzed based on an algorithm defined by the Bayesian network model. The results identify whether a patient is in a state with SB characteristics. Then, each respondent is placed on a continuum of discomfort/well-being and fragility. This tool also considers risk factors and protective factors. The results from Barros et al. [5] identified areas of interest for particular psychotherapeutic interventions for each respondent: a) feelings of satisfaction/dissatisfaction with life; b) state of satisfaction/dissatisfaction with oneself and achievements; and c) reasons to live/stay alive if you are thinking about committing suicide. An example of the results is presented in the results section below.

\section{Data collection}

Potential participants were asked to sign a written informed consent form and were then asked to respond 
to the questions included in the following instruments: Outcome Questionnaire (OQ-45.2), State-Trait Anger Expression Inventory (STAXI-2), Reasons for Living Scale (RFL), Depressive Experience Questionnaire (DEQ), Family APGAR, and sociodemographic and clinical questionnaires. Detailed descriptions of these questionnaires can be found in Barros et al. [5] and Morales et al. [25].

Participants were guided through the questionnaires and written consent form by specially trained evaluators. If participants were minors, the consent form was signed in writing by their guardian or caregiver. The probability and protocol were approved by the institutional ethics committees of the School of Medicine at the Catholic University of Chile and the Sótero del Río Hospital.

The aims and methodology of the study were explained to participants, as well as the unpaid nature of their participation. Costs, risks of participating in the study, the voluntary nature of participation, the right to withdraw from the study, and confidentiality were also explained. Authorizations from treating physicians were also requested for patients' participation in the study, and any potential deterioration in the patients' mental states during the study was to be noted. No incidents were recorded during this study. Participants were also offered the opportunity to inquire further about the study by contacting the principal investigator. Health clinicians, researchers, and mathematical analysts collaborated in offering assistance to participants throughout the study.

\section{Descriptive analysis of the data}

Participants were categorized into the following two groups: 1) with suicidal behavior, as indicated by attendance of consultations regarding a suicide attempt or suicidal ideation within the preceding year $(n=326) ; 2)$ without suicidal behavior, as indicated by attendance of mental health consultations with no suicide attempt or signs of suicidal ideation within the preceding year $(n=$ 324). The sample included 650 ambulatory mental health patients between the ages of 14 and 85 (adolescents, young adults, adults, and seniors) who were recruited between June 2010 and December 2014. Of this sample, $95.38 \%$ had been diagnosed with mood disorders (DSM IV-R). Among the total sample, the average age was $39.77 \pm 15.03$, with an age range between 14 and 83 years old. There were 517 women (79.54\%) and 133 men (20.46\%). Sociodemographic characteristics are detailed in Table 1.

The total sample was also mainly characterized by patients diagnosed with affective disorders, most commonly major depressive disorder $(43.38 \% ; n=282)$, of whom $28.09 \%(n=91)$ had not exhibited SB (attempt or ideation) during the past year, and $58.59 \%(n=191)$ had attempted suicide. Of the 191 patients with SB who had been diagnosed with major depressive disorder, $26.18 \%$ $(n=50)$ made high-severity suicide attempts, $19.90 \%$ $(n=38)$ made low-severity suicide attempts, and 53.93\% $(n=103)$ presented suicidal ideation. Low-severity suicide attempts were characterized by minimal intentions of dying, the low subjective or objective lethality of the attempt, and the deployment of efforts to be saved after the suicide attempt. On the other hand, high-severity suicide attempts were characterized by strong intentions to die as well as high subjective and objective lethality, with no efforts to be saved being made after the attempt. The psychiatric diagnoses are shown in Table 2.

Regarding the age distribution, the total sample included patients in the following age groups: $14-19$ years old ( $n=76 ; 11.69 \%) ; 20-29$ years old $(n=119 ; 18.31 \%)$; $30-39$ years old $(n=123 ; 18.92 \%) ; 40-49$ years old $(n=$ $125 ; 19.23 \%) ; 50-59$ years old $(n=146 ; 22.46 \%) ; 60$ years and up $(n=61 ; 9.38 \%)$. The age distributions are shown in Table 3.

\section{Data analysis}

Given the large number of variables currently available, it was necessary to perform a feature selection to narrow down what was to be modeled. This approach follows the principle of parsimony, indicating that if two models show the same performance, the model that has a smaller number of variables would be preferred. Consequently, considering previous work, we based the analysis of this study on two primary explorations using SVM and DT, as explained above. The software was R Project for Statistical Computer (R [31]).

\section{Initial data processing}

The results from the previous SVM analysis provided a model that selected 22 variables, which, depending on the circumstances, could define whether a person was in a suicide risk zone (accuracy $=0.78$, sensitivity $=0.77$, and specificity $=0.79$ ). The assessment of all these variables allowed a determination of whether a patient was at risk of attempting suicide or was actively thinking of attempting suicide. Interrelationships between these variables were multiple and contributed to the particular ways in which variables were configured for each case. The metrics and analysis are presented in [5].

The results from the DT analysis showed the flow of responses as a trajectory of psychological variables that constituted a current situation of suicide risk (or no risk). Four trees distinguishing the groups were established, and the elements of one tree were analyzed in greater detail since they included both clinical and personality variables. This tree consisted of six nodes without suicide risk and eight nodes with suicide risk. Decision tree 01 had a 0.674 accuracy value, a 0.652 
Table 1 Sociodemographic characteristics of the sample, differences between groups

\begin{tabular}{|c|c|c|c|}
\hline Variable & Total & $\begin{array}{l}\text { Group without current } \\
\text { suicidal behavior }\end{array}$ & $\begin{array}{l}\text { Group with } \\
\text { suicidal behav }\end{array}$ \\
\hline Women & $517(79.54 \%)$ & $257(79.32 \%)$ & $260(79.75 \%)$ \\
\hline Men & $133(20.46 \%)$ & $67(20.68 \%)$ & $66(20.25 \%)$ \\
\hline \multicolumn{4}{|l|}{ Chi-squared Test } \\
\hline \multicolumn{4}{|l|}{ Age } \\
\hline Average & 39.77 & 42.13 & 37.42 \\
\hline Standard deviation & 15.03 & 14.8 & 14.91 \\
\hline \multicolumn{4}{|l|}{ T-Student Test } \\
\hline \multicolumn{4}{|l|}{ Education level } \\
\hline Without higher education & $336(51.69 \%)$ & $178(54.94 \%)$ & $158(48.47 \%)$ \\
\hline With higher education & $314(48.31 \%)$ & $146(45.06 \%)$ & $168(51.53 \%)$ \\
\hline \multicolumn{4}{|l|}{ Chi-squared Test } \\
\hline \multicolumn{4}{|l|}{ Living with } \\
\hline Alone & $67(10.31 \%)$ & $31(9.57 \%)$ & $36(11.04 \%)$ \\
\hline Couple & $84(12.92 \%)$ & 49 (15.12\%) & 35 (10.74\%) \\
\hline Family & $499(76.77 \%)$ & $244(75.31 \%)$ & $255(78.22 \%)$ \\
\hline
\end{tabular}

Chi-squared Test

$X=2.943$

$\mathrm{df}=2$

$p$-value $=0.2296$

Marital status

$\begin{array}{ll}\text { Single } & 271(41.69 \%) \\ \text { Married } & 238(36.62 \%) \\ \text { Free union } & 31(4.77 \%) \\ \text { Separated o widowed } & 110(16.92 \%)\end{array}$

Chi-squared Test

Children

Average

Standard deviation

1.438

1.556

1.373

1.509

T-Student Test

Occupation

$\begin{array}{ll}\text { Within_working_force } & 329(50.62 \%) \\ \text { Student } & 142(21.85 \%) \\ \text { Unemployed } & 39(6 \%)\end{array}$
$115(35.49 \%)$
$135(41.67 \%)$
$18(5.56 \%)$
$56(17.28 \%)$

$156(47.85 \%)$
$103(31.6 \%)$
$13(3.99 \%)$
$54(16.56 \%)$

$$
\begin{aligned}
& X=11.34 \\
& d f=3
\end{aligned}
$$

$p$-value $=0.01001 *$

1.503

1.601

$$
\begin{aligned}
& t=-1.062 \\
& d f=646.2 \\
& p \text {-value }=0.2887
\end{aligned}
$$
$142(43.56 \%)$
$90(27.61 \%)$
21 (6.44\%)

$X=0.001583$

$\mathrm{df}=1$

$p$-value $=0.9683$

$\mathrm{t}=4.041$

$\mathrm{df}=648$

$p$-value $=5.955 \mathrm{e}-05 * *$ $\mathrm{df}=1$
$p$-value $=0.1158$
$p$-value $=0.244$ 
Table 1 Sociodemographic characteristics of the sample, differences between groups (Continued)

\begin{tabular}{|c|c|c|c|c|}
\hline Variable & Total & $\begin{array}{l}\text { Group without current } \\
\text { suicidal behavior }\end{array}$ & $\begin{array}{l}\text { Group with } \\
\text { suicidal behavior }\end{array}$ & Test \\
\hline Housewife & 127 (19.54\%) & $60(18.52 \%)$ & 67 (20.55\%) & \\
\hline not_working & $13(2 \%)$ & 7 (2.16\%) & $6(1.84 \%)$ & \\
\hline \multirow[t]{3}{*}{ Chi-squared Test } & & & & $X=17.01$ \\
\hline & & & & $\mathrm{df}=4$ \\
\hline & & & & $p$-value $=0.001923 *$ \\
\hline
\end{tabular}

Note: ${ }^{*} p<0.05 ;{ }^{* *} p<0.001$

precision value, a 0.678 recall value, a 0.670 specificity value, an F measure of 0.665 , and a $73.35 \%$ receiver operating characteristic (ROC) area under the curve (AUC). Decision tree 02 had a 0.669 accuracy, a 0.642 precision, a 0.694 recall, a 0.647 specificity, a $0.667 \mathrm{~F}$ measure, and a 68.91\% ROC AUC. Decision tree 03 yielded a 0.681 accuracy value, a 0.675 precision value, a 0.638 recall value, a 0.721 specificity value, a $0.656 \mathrm{~F}$ measure, and a $65.86 \%$ ROC AUC. Decision tree 04 showed a 0.714 accuracy value, a 0.734 precision value, a 0.628 recall value, a 0.792 specificity value, a $0.677 \mathrm{~F}$ measure, and a $58.85 \%$ ROC AUC. The metrics and analysis are described in [25].

Taking the prior findings as inputs (i.e., the support vector machine and decision tree results mentioned above), we started with 25 variables. These variables were grouped and reprocessed into categories as follows: demographics were categorized as discrete values for classification, the Reasons for Living (RFL) questions were grouped into two variables, and question 25 of the Reasons For Living Questionnaire was kept separate because it was shown to be a relevant variable on its own, while the remaining questions were grouped as a single variable (due to strong correlations among them as seen in Fig. 1) by using the averages of their values; items from the Outcome Questionnaire (OQ) were grouped into a single variable (due to strong correlations among them) by using the averages of their values, except for question 8 from the Outcome Questionnaire, which was kept separate because of its relevance as a question on its own [18, 37]. Figure 2 presents a matrix of correlations between the selected questions from the Outcome Questionnaire.

Table 2 Psychiatric diagnoses distribution, differences between groups

\begin{tabular}{|c|c|c|c|c|c|c|c|c|}
\hline Variable N (\%) & Total & $\begin{array}{l}\text { Group without current } \\
\text { suicidal behavior }\end{array}$ & $\begin{array}{l}\text { Group with } \\
\text { suicidal behavior }\end{array}$ & & $\begin{array}{l}\text { Suicide attempt } \\
\text { high severity }\end{array}$ & $\begin{array}{l}\text { Suicide attempt } \\
\text { low severity }\end{array}$ & $\begin{array}{l}\text { Suicide } \\
\text { ideation }\end{array}$ & $\begin{array}{l}\text { Sub- } \\
\text { total }\end{array}$ \\
\hline $\begin{array}{l}\text { Major depressive } \\
\text { disorder }\end{array}$ & $\begin{array}{l}282 \\
(43.38 \%)\end{array}$ & 91 (28.09\%) & 191 (58.59\%) & & 50 (26.18\%) & $38(19.90 \%)$ & $\begin{array}{l}103 \\
(53.93 \%)\end{array}$ & 191 \\
\hline Bipolar disorder & $\begin{array}{l}105 \\
(16.15 \%)\end{array}$ & 59 (18.21\%) & $46(14.11 \%)$ & & 8 (17.39\%) & 12 (26.09\%) & $\begin{array}{l}26 \\
(56.52 \%)\end{array}$ & 46 \\
\hline $\begin{array}{l}\text { Moderate } \\
\text { depressive disorder }\end{array}$ & $\begin{array}{l}54 \\
(8.31 \%)\end{array}$ & 32 (9.88\%) & $22(6.75 \%)$ & & 4 (18.18\%) & 8 (36.36\%) & $\begin{array}{l}10 \\
(45.45 \%)\end{array}$ & 22 \\
\hline $\begin{array}{l}\text { Mild depressive } \\
\text { disorder }\end{array}$ & $\begin{array}{l}12 \\
(1.85 \%)\end{array}$ & $11(3.4 \%)$ & $1(0.31 \%)$ & & $0(0 \%)$ & $0(0 \%)$ & $\begin{array}{l}1 \\
(100 \%)\end{array}$ & 1 \\
\hline $\begin{array}{l}\text { Adjustment } \\
\text { disorder }\end{array}$ & $\begin{array}{l}70 \\
(10.77 \%)\end{array}$ & 45 (13.89\%) & 25 (7.67\%) & & $5(20.00 \%)$ & $12(48.00 \%)$ & $\begin{array}{l}8 \\
(32 \%)\end{array}$ & 25 \\
\hline Anxiety disorder & $\begin{array}{l}75 \\
(11.54 \%)\end{array}$ & $53(16.36 \%)$ & 22 (6.75\%) & & $4(18.18 \%)$ & $4(18.18 \%)$ & $\begin{array}{l}14 \\
(63.64 \%)\end{array}$ & 22 \\
\hline Mixed episode & $\begin{array}{l}15 \\
(2.31 \%)\end{array}$ & $13(4.01 \%)$ & $2(0.61 \%)$ & & $1(50.00 \%)$ & $0(0 \%)$ & $\begin{array}{l}1 \\
(50 \%)\end{array}$ & 2 \\
\hline Other disorders & $\begin{array}{l}30 \\
(4.62 \%)\end{array}$ & 16 (4.94\%) & 14 (4.29\%) & & 5 (35.71\%) & 3 (21.43\%) & $\begin{array}{l}6 \\
(42.86 \%)\end{array}$ & 14 \\
\hline Dysthymia & $\begin{array}{l}7 \\
(1.08 \%)\end{array}$ & $4(1.23 \%)$ & $3(0.92 \%)$ & & 2 (66.67\%) & $0(0 \%)$ & $\begin{array}{l}1 \\
(33.33 \%)\end{array}$ & 3 \\
\hline \multirow[t]{3}{*}{ Chi-squared Test } & & & & $X=74.12$ & & & & 326 \\
\hline & & & & $d f=8$ & & & & \\
\hline & & & & $\underset{* *}{p \text {-value }=7.397 e-13}$ & & & & \\
\hline
\end{tabular}


Table 3 Age distribution, differences between groups

\begin{tabular}{|c|c|c|c|c|}
\hline $\begin{array}{l}\text { Variable } \\
\mathrm{N}(\%)\end{array}$ & Total & $\begin{array}{l}\text { Group without } \\
\text { current suicidal behavior }\end{array}$ & $\begin{array}{l}\text { Group with } \\
\text { suicidal behavior }\end{array}$ & Test \\
\hline 14-19years & 76 (11.69\%) & $24(7.41 \%)$ & $52(15.95 \%)$ & \\
\hline 20-29 years & $119(18.31 \%)$ & $54(16.67 \%)$ & 65 (19.94\%) & \\
\hline 30-39 years & $123(18.92 \%)$ & $57(17.59 \%)$ & 66 (20.25\%) & \\
\hline 40-49 years & $125(19.23 \%)$ & $72(22.22 \%)$ & $53(16.26 \%)$ & \\
\hline 50-59 years & $146(22.46 \%)$ & $75(23.15 \%)$ & 71 (21.78\%) & \\
\hline 60 years and more & $61(9.38 \%)$ & $42(12.96 \%)$ & 19 (5.83\%) & \\
\hline \multirow[t]{3}{*}{ Chi-squared Test } & & & & $x=23.65$ \\
\hline & & & & $d f=5$ \\
\hline & & & & $p$-value $=0.0002529 * *$ \\
\hline
\end{tabular}

Note: ${ }^{*} p<0.05 ;{ }^{* *} p<0.001$

The Depressive Experience Questionnaire (DEQ) underwent a different preprocessing procedure. Correlations among the variables were weak (Fig. 3). Therefore, a principal component analysis (PCA) was performed with standardized variables [32], and the first two main components that explained $56.437 \%$ of the variance were chosen (Table 4). The first main component, called "low self-esteem", included the being unable to accept personal plans and goals, having feelings of inner emptiness, becoming terrified when alone, having feelings of personal distress linked to success/failure, being concerned about what others can provide in relationships, and having feelings of dissatisfaction with oneself. This first component had higher coefficients associated with variables DEQ_16 and DEQ_19 and lower scores associated with variables DEQ_56 and DEQ_62, with negative

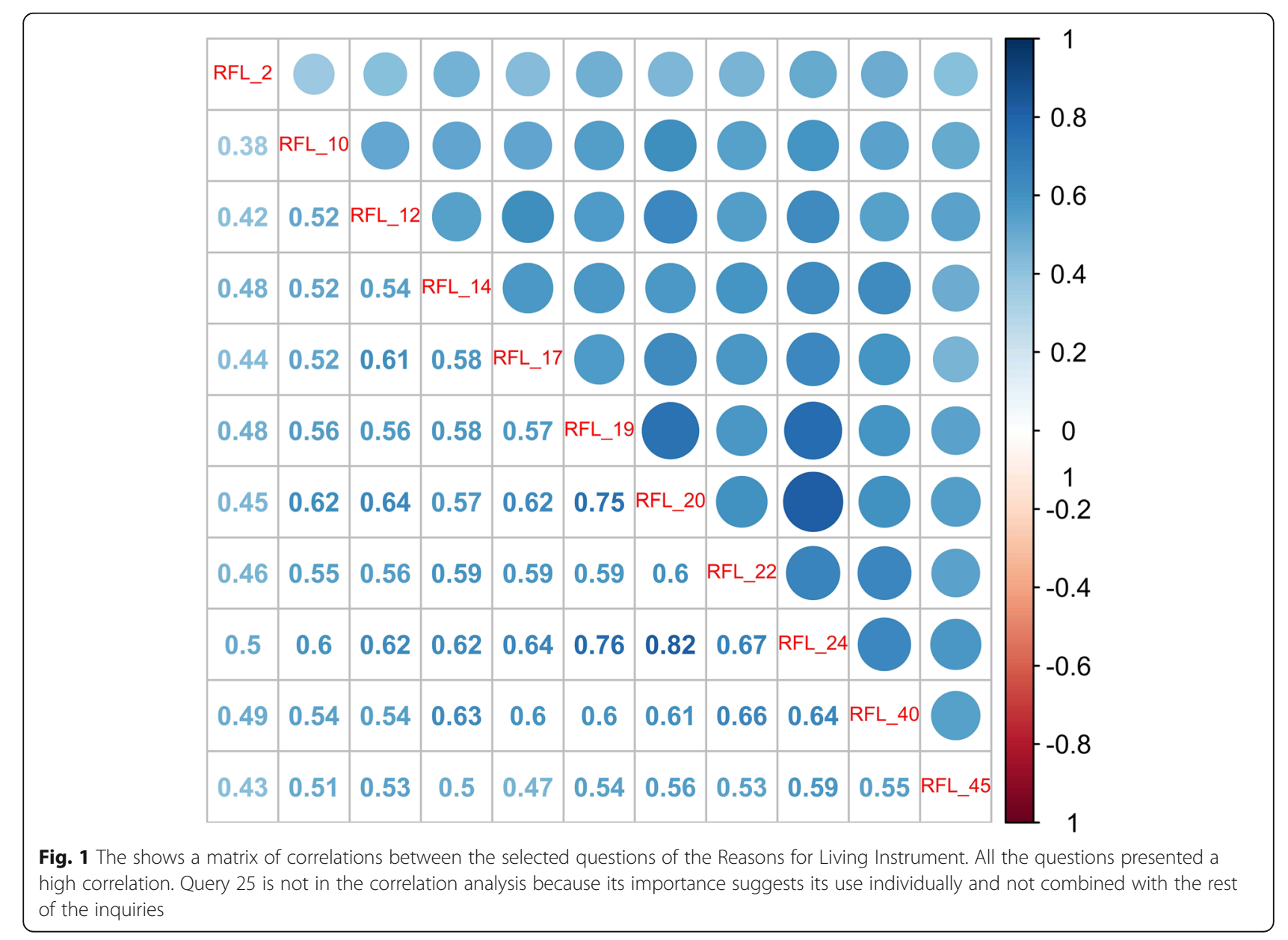




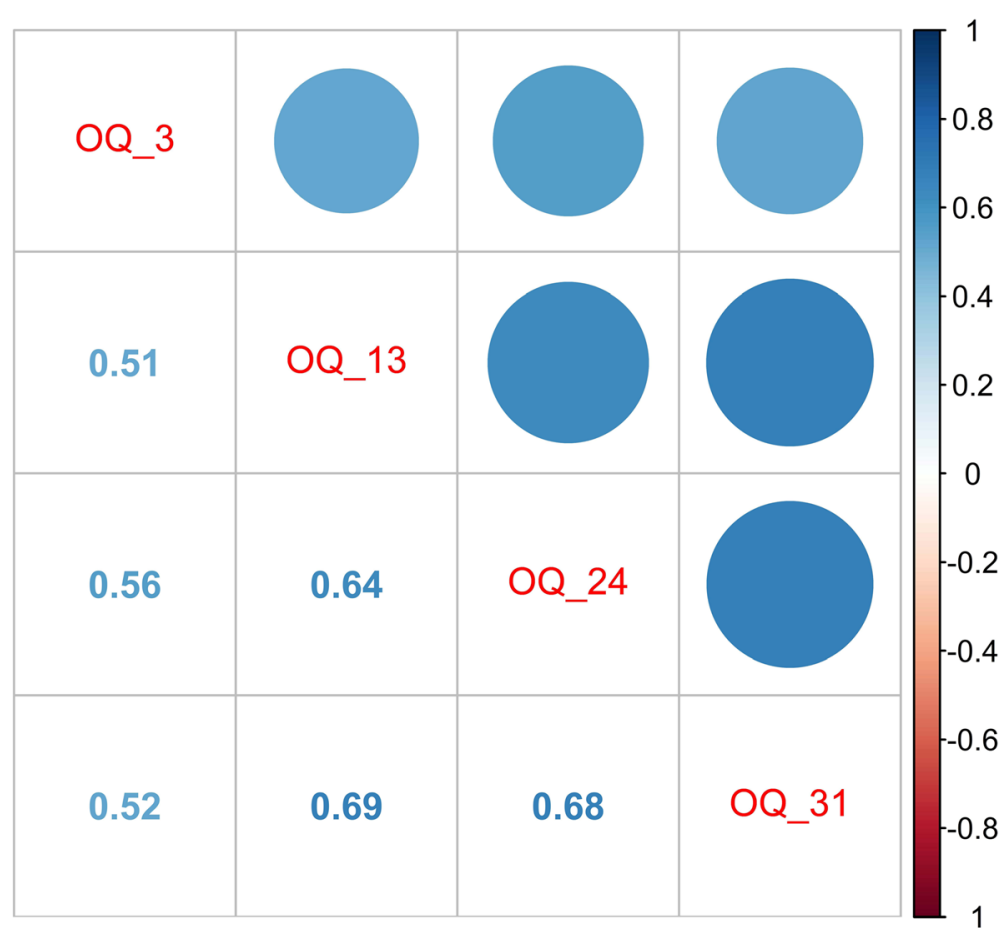

Fig. 2 The figure presents a matrix of correlations between the selected questions of the Outcome Questionnaire. The four chosen variables where highly correlated. Query 8 is not in the correlation analysis because its importance suggests its use individually and not combined with the rest of the inquiries

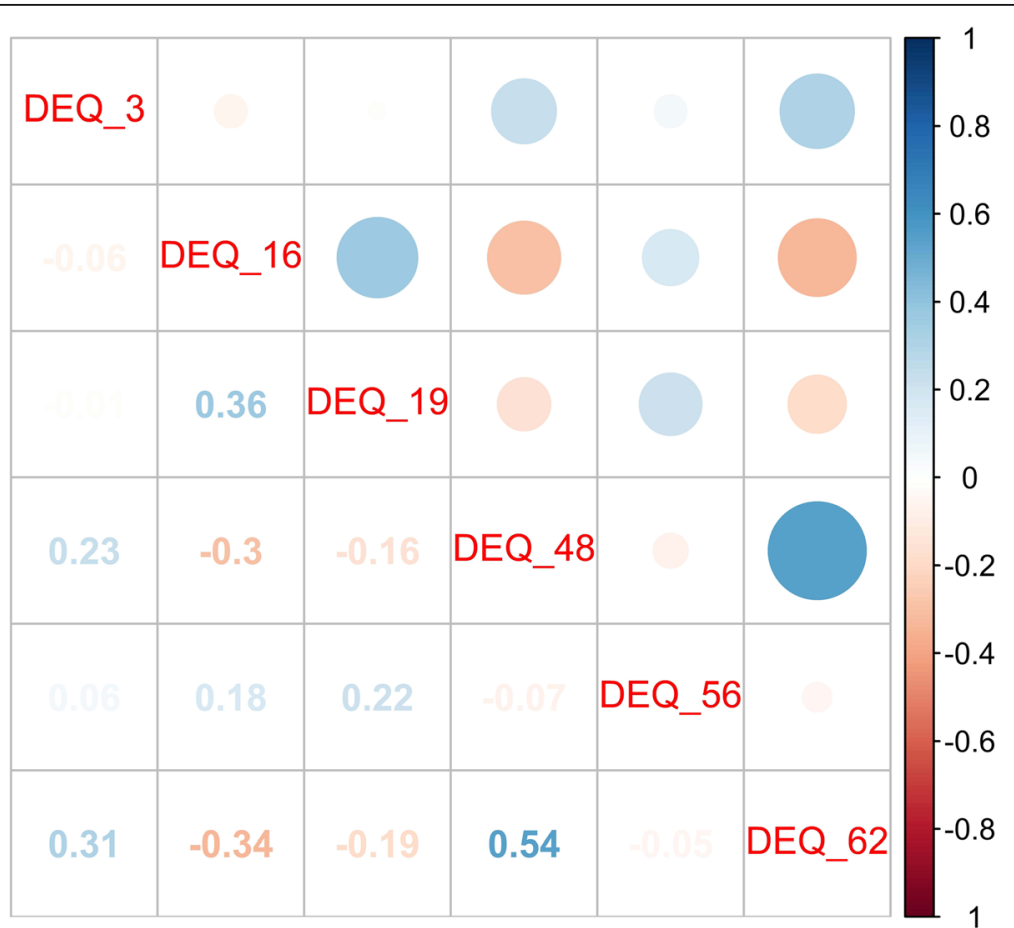

Fig. 3 The figure shows a matrix of correlations between the selected questions of the Depressive Experience Questionnaire. The chosen variables do not show a significant correlation between them 
Table 4 Ratio of variance explained DEQ Main Components and Coefficients of PC! Also, PC2

\begin{tabular}{|c|c|c|c|c|c|c|}
\hline & PC1 & PC2 & PC3 & PC4 & PC5 & PC6 \\
\hline Standard deviation & 1.452 & 1.131 & 0.905 & 0.869 & 0.770 & 0.668 \\
\hline Proportion of Variance & 0.351 & 0.213 & 0.137 & 0.126 & 0.099 & 0.074 \\
\hline Cumulative Proportion & 0.351 & 0.564 & 0.701 & 0.827 & 0.926 & 1.000 \\
\hline Coefficients DEQ_Question_3 & -0.277 & 0.515 & & & & \\
\hline DEQ_Question_16 & 0.464 & 0.286 & & & & \\
\hline DEQ_Question_19 & 0.357 & 0.471 & & & & \\
\hline DEQ_Question_48 & -0.509 & 0.234 & & & & \\
\hline DEQ_Question_56 & 0.184 & 0.555 & & & & \\
\hline DEQ_Question_62 & -0.537 & 0.262 & & & & \\
\hline
\end{tabular}

effects on the latter two variables. The second main component, called "interpersonal sensitivity", included accepting personal plans and goals, setting very high goals, becoming terrified when alone, fluctuating between feeling big and small, not feeling jealous in relationships, and needing things that only others can provide. Variables for the second component all had coefficients greater than 0 , and the variables from items 3, 19 , and 56 of the DEQ had the greatest impact on this component. The quadrants were configured with the following distribution:

- 00: Patients with low scores for main components 1 and 2 (high self-esteem and low interpersonal sensitivity);
- 01: Patients with a low score for main component 1 and a high score for main component 2 (high selfesteem and high interpersonal sensitivity);

- 10: Patients with a high score for main component 1 and a low score for main component 2 (low selfesteem and low interpersonal sensitivity);

- 11: Patients with high scores for main components 1 and 2 (low self-esteem and high interpersonal sensitivity) (Table 5).

The coefficients of the DEQ variables for each of the two components are shown in Table 4 and Fig. 4. Feature transformation for the DEQ variables was necessary to narrow the scope of the problem. Regarding this questionnaire, the selected components rather than the

Table 5 Coefficients and description of two main components

\begin{tabular}{|c|c|c|c|}
\hline & PC1 & Main Component $n^{\circ} 1$ & PC1 low self-esteem. \\
\hline DEQ_PRE_3 & -0.277 & $\begin{array}{l}\text { Disagreeing with the statement "I feel comfortable with my personal } \\
\text { plans and goals rather than trying to aim for something more" }\end{array}$ & (inability to accept personal plans and goals). \\
\hline DEQ_PRE_16 & 0.464 & Agreeing with the statement "sometimes I feel empty inside". & (having feelings of inner emptiness). \\
\hline DEQ_PRE_19 & 0.357 & Agreeing with the statement "I become terrified when I feel alone". & (becoming terrified when alone). \\
\hline DEQ_PRE_48 & -0.509 & $\begin{array}{l}\text { Disagreeing with the statement "I feel good within myself whether } \\
\text { I succeed or fail". }\end{array}$ & (feelings of personal distress linked to success-failure). \\
\hline DEQ_PRE_56 & 0.184 & $\begin{array}{l}\text { Agreeing with the statement "When it comes to my relationships } \\
\text { with others, I am very concerned about what they provide me." }\end{array}$ & $\begin{array}{l}\text { (being concerned with that others can provide in } \\
\text { relationships). }\end{array}$ \\
\hline \multirow[t]{2}{*}{ DEQ_PRE_62 } & -0.537 & $\begin{array}{l}\text { Agreeing with the statement "I am very satisfied with myself and } \\
\text { with what I have achieved." }\end{array}$ & $\begin{array}{l}\text { (feelings of dissatisfaction with oneself and with one's } \\
\text { achievements). }\end{array}$ \\
\hline & PC2 & Main Component $n^{\circ} 2$ & PC2 Interpersonal sensitivity. \\
\hline DEQ_PRE_3 & 0.515 & $\begin{array}{l}\text { Agreeing with the statement "in general, I feel comfortable with } \\
\text { my personal plans and goals rather than trying to aim for } \\
\text { something more". }\end{array}$ & (acceptance of personal plans and goals). \\
\hline DEQ_PRE_16 & 0.286 & Agreeing with the statement "I set myself very high goals". & (setting very high goals). \\
\hline DEQ_PRE_19 & 0.471 & Agreeing with the statement "I become terrified when I feel alone." & (becoming terrified when alone). \\
\hline DEQ_PRE_48 & 0.234 & $\begin{array}{l}\text { Agreeing with the statement "sometimes I feel very big and at } \\
\text { other times I feel very small". }\end{array}$ & (fluctuating between feeling big and small). \\
\hline DEQ_PRE_56 & 0.555 & $\begin{array}{l}\text { Agreeing with the statement "when I am involved with someone, } \\
\text { I never feel jealous". }\end{array}$ & (not feeling jealous in relationships). \\
\hline DEQ_PRE_62 & 0.262 & $\begin{array}{l}\text { Agreeing with the statement "I really need things that only other } \\
\text { people can give me". }\end{array}$ & (needing things that only others can provide). \\
\hline
\end{tabular}


a

Main components quadrants and coefficients of Depressive Experience Questionnaire.

PC1 characterized by 'low self-esteem'.

PC2 characterized by 'interpersonal sensitivity'.
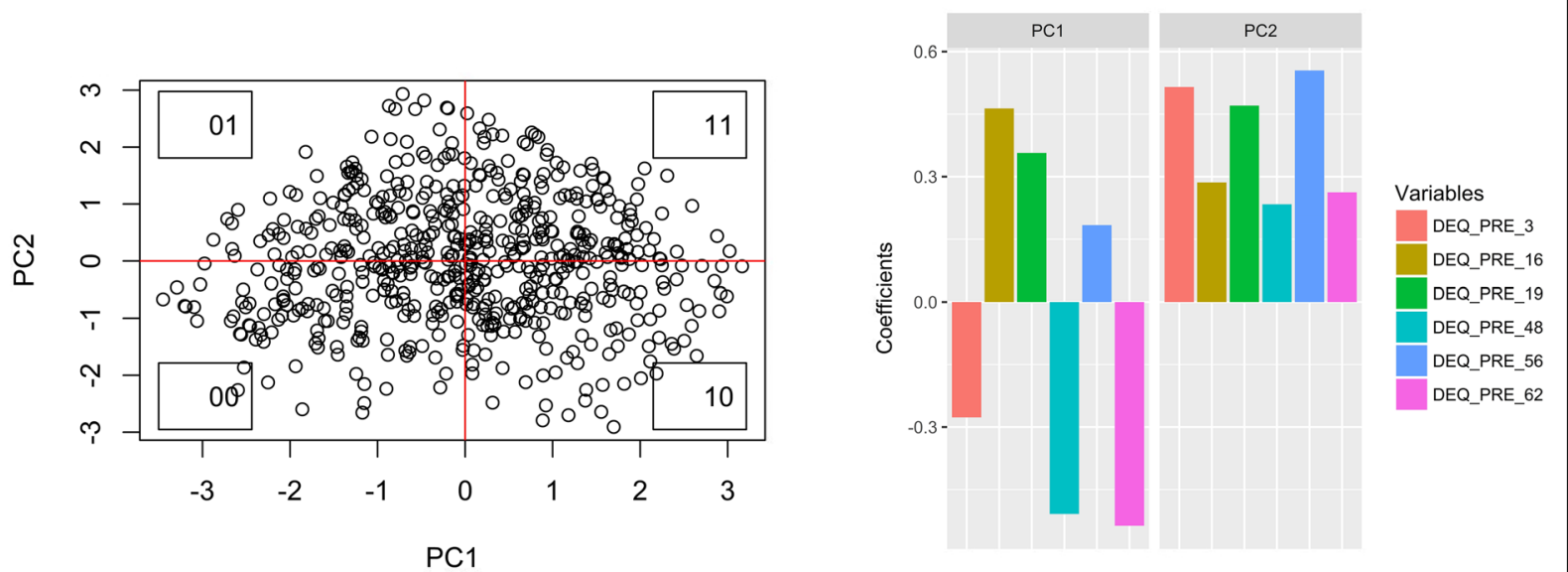

b

Model Calibration.

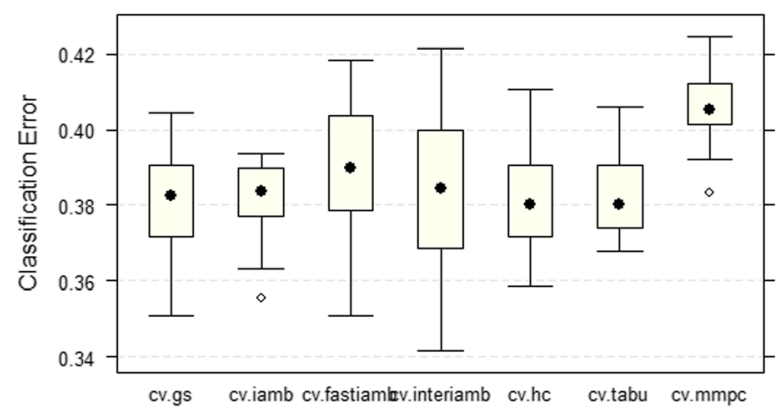

Fig. 4 a The figure displays a Principal Component Analysis performed with the DEQ variables, selecting the first two principal components. The first graph shows the distribution of the projected points in these two components. The second graph shows the contribution of each of the DEQ questions to the first two principal components. b Shows classification error obtained in the model calibration process, using different search algorithms. The Tabu search algorithm was selected due to its lower average classification error and lower variance in the cross-validation sample

original variables were used to calibrate the Bayesian network model.

With the new feature obtained from the DEQ variables, in the total sample, $24.3 \%(n=158)$ of patients had high self-esteem and low interpersonal sensitivity, $24.3 \%$ $(\mathrm{n}=158)$ of patients had high self-esteem and high interpersonal sensitivity, 26.3\% $(n=171)$ of patients had low self-esteem and low interpersonal sensitivity, and 25,1\% $(n=163)$ of patients had low self-esteem and high interpersonal sensitivity.

Meanwhile, participants in the group with SB had the following characteristics: $15.3 \%(n=50)$ of patients had high self-esteem and low interpersonal sensitivity, $17.4 \%$ $(n=57)$ of patients had high self-esteem and high interpersonal sensitivity, $38.2 \%(n=125)$ of patients had low self-esteem and low interpersonal sensitivity, and $29.1 \%$ $(n=95)$ of patients had low self-esteem and high interpersonal sensitivity.

\section{Model calibration}

The calibration of the model was achieved using crossvalidation. The process consists of two stages:

1) Learning the structure of the network. 
2) Learning the parameters of the network.

For the first stage, a mixed approach based on a) clinical expertise and knowledge and b) heuristics was used to learn the structure from the data. Based on clinical expertise and domain knowledge, an initial graph was defined regarding the relationships that we wanted to keep in the structure based on their clinical relevance. Additionally, a set of 'blacklisted' arcs were defined if the arcs that we did not want were part of the graph. This graph is shown in Fig. 5. Then, the structure of the final graph was completed by using a search algorithm, and several methods were tested in the calibration process (Grow-Shrink, Incremental Association, Fast Incremental Association, Interleaved Incremental Association, Hill-Climbing, Tabu search, and Max-min Parents and Children).

New relationships were formed according to the existing correlations in the data, which generated the Bayesian network seen in Fig. 6.

Subsequently, with the structure for each algorithm already in place, parameters associated with joint probability distributions were calibrated using the data and the Bayesian method for estimating parameters. Finally, the tabu search algorithm [28] was selected based on its lower average classification error and lower error classification variance over the crossvalidation process. The results of the search algorithm calibration are shown in Fig. 4b.

\section{Evaluating model fit}

As indicated above, the cross-validation technique was used to calibrate the structure and parameters. To determine the model fitness of the calibration process, the same technique was used, and the leave-one-out cross-validation method was also used to evaluate the final model. In both cases, we calculated precision and other relevant performance measures of the resulting model, and the details of each method are presented as follows.

1) The leave-one-out cross-validation method (LOOCV) was used, in which the model was trained with N-1 cases and its accuracy was calculated for

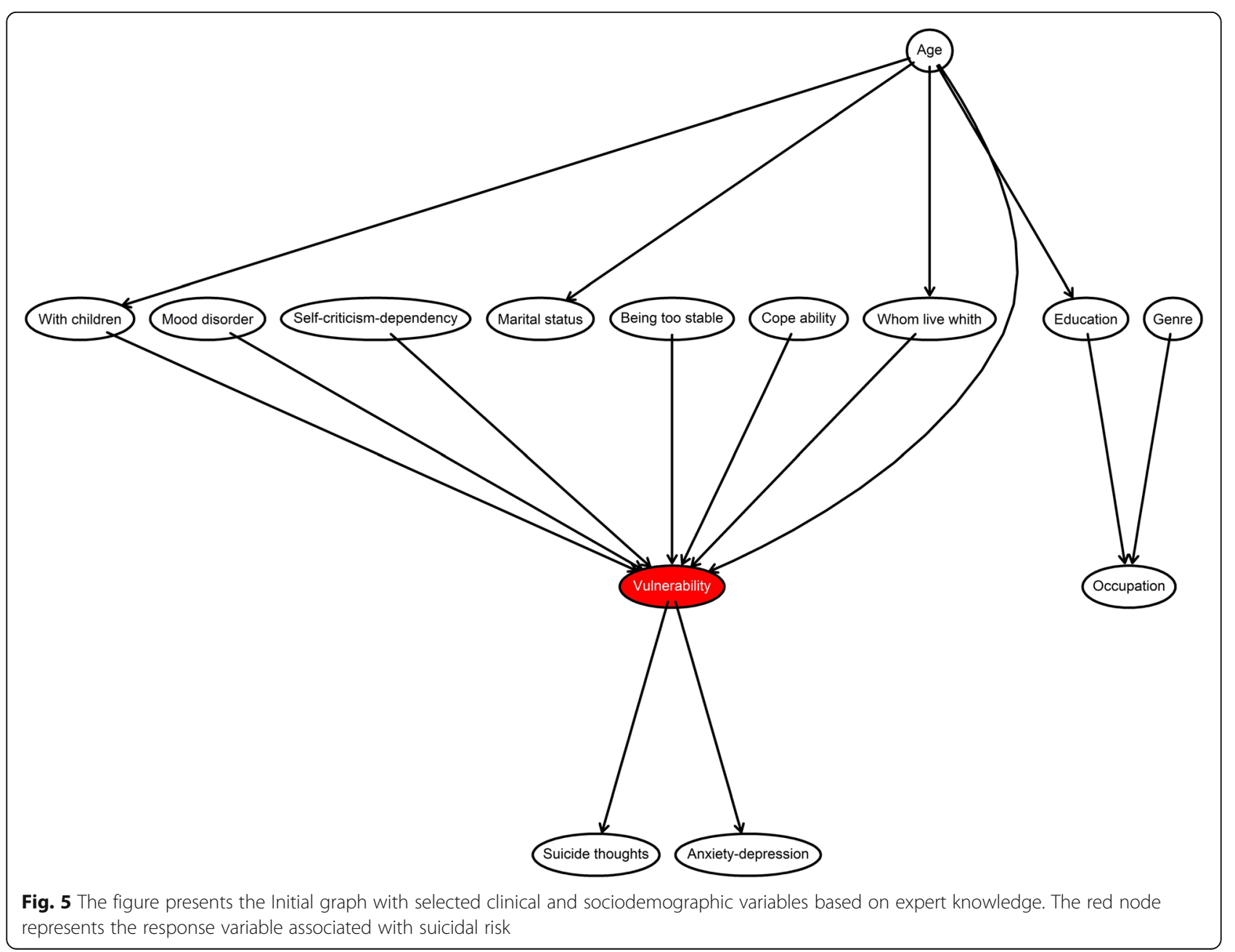




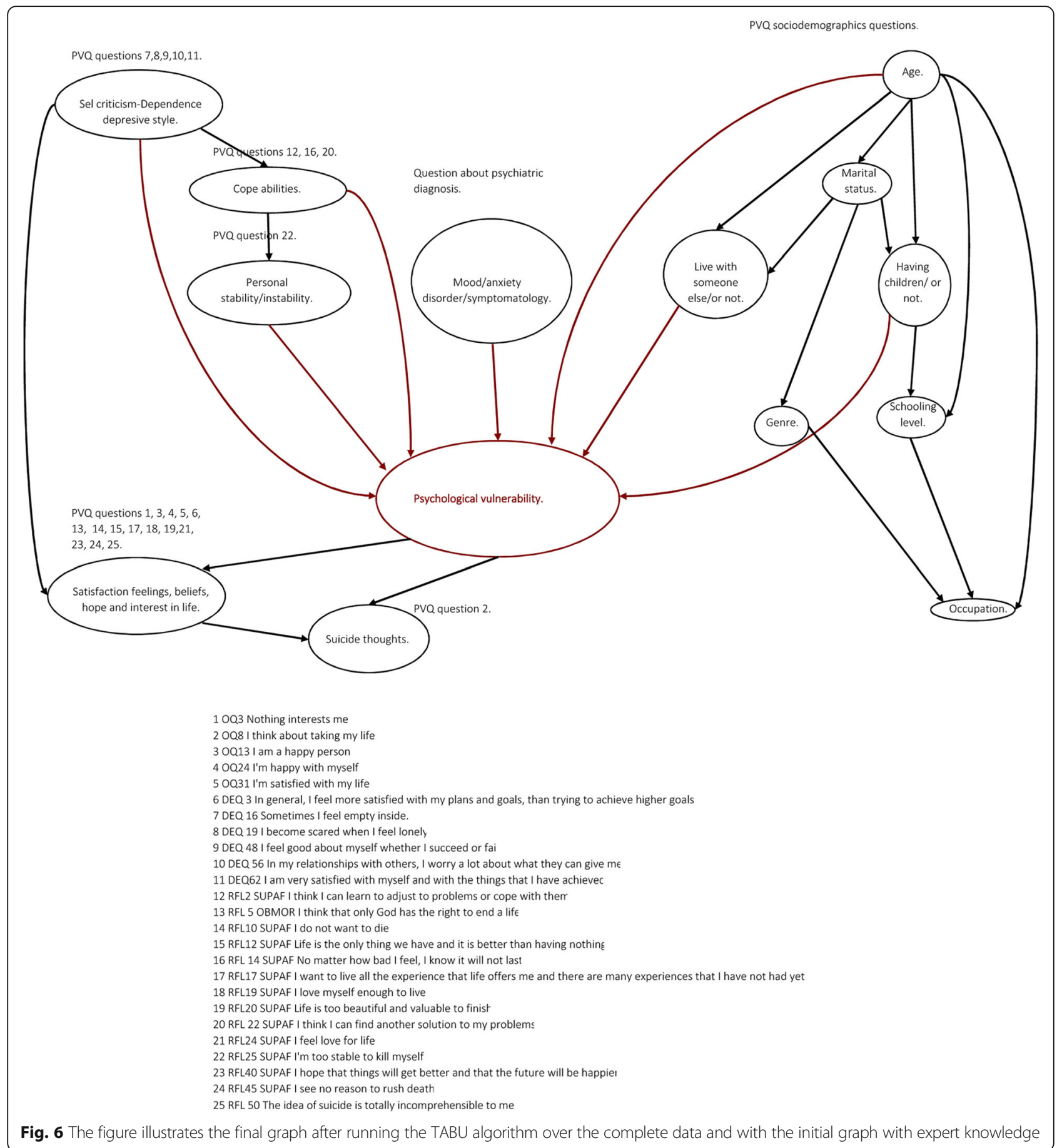

the remaining cases (those that were not used for training). This procedure was repeated for each group of data, and the success average was equivalent to the precision estimator. With the LOOCV method, the Bayesian network model fit was 0.7046 . The indicators are shown in Table 6.

2) Repeated 10-fold cross-validation was applied to calculate the model fit by repeating the process 100 times, which gave an average accuracy value of 0.701 (Fig. 7).
The results were used to develop a psychological evaluation questionnaire. This instrument has 25 items that are answered on a Likert scale. These questions can be asked by professionals in contact with individuals who are potentially at risk of attempting suicide. The person administering the questions need not be an expert but should be trained to ask the questions. Details of these questions can be seen in the Psychological Vulnerability Questionnaire shown in Table 7. 
Table 6 Bayesian Network evaluating model fit using Leaveone-out cross-validation (LOOCV)

\begin{tabular}{ll}
\hline Metrics & Value \\
\hline Sensitivity & 0.6840 \\
Specificity & 0.7253 \\
Pos Pred Value & 0.7147 \\
Neg Pred Value & 0.6953 \\
Precision & 0.7147 \\
Recall & 0.6840 \\
F1 & 0.6991 \\
Prevalence & 0.5015 \\
Detection Rate & 0.3431 \\
Detection Prevalence & 0.4800 \\
Balanced Accuracy & $\mathbf{0 . 7 0 4 7}$ \\
\hline
\end{tabular}

The results identified whether the participant being evaluated was in a fragile state that made him or her vulnerable to actively thinking about suicide or attempting to commit suicide. As mentioned above, this assessment tool shows protective and risk factors for each patient, which might guide evaluators and clinicians toward indicating aspects of interest for psychotherapeutic intervention. A patient profile description was elaborated in terms of the following: a) Feelings of satisfaction/dissatisfaction with life.

b) State of satisfaction/dissatisfaction with oneself and achievements.

c) Reasons to live/to stay alive if one is thinking about attempting suicide.

\section{Results}

The raw results of the analysis, and later results including expert analysis, showed that there were categories that interacted to configure a state of vulnerability. These attributes differentiated the state stems from trait stems. In addition, some of the attributes were factors that had an impact on suicide risk, while others coexisted or appeared as symptoms (or vulnerability). The following interrelationships between attributes were observed: 1) having an impact on vulnerability; 2) coexisting and being relatively stable over time; and 3) being part of the state of psychological vulnerability.

The attributes that had an impact on state stems of vulnerability were sociodemographic in nature, such as gender, age, marital status, number of children or coinhabitants, level of schooling, occupation, and diagnosis. The attributes that coexisted, which were trait stems, were relatively stable and were associated with personality. These attributes were from the quadrant of selfcriticism/dependency depressive experience styles, as observed in personal descriptions with regards to the

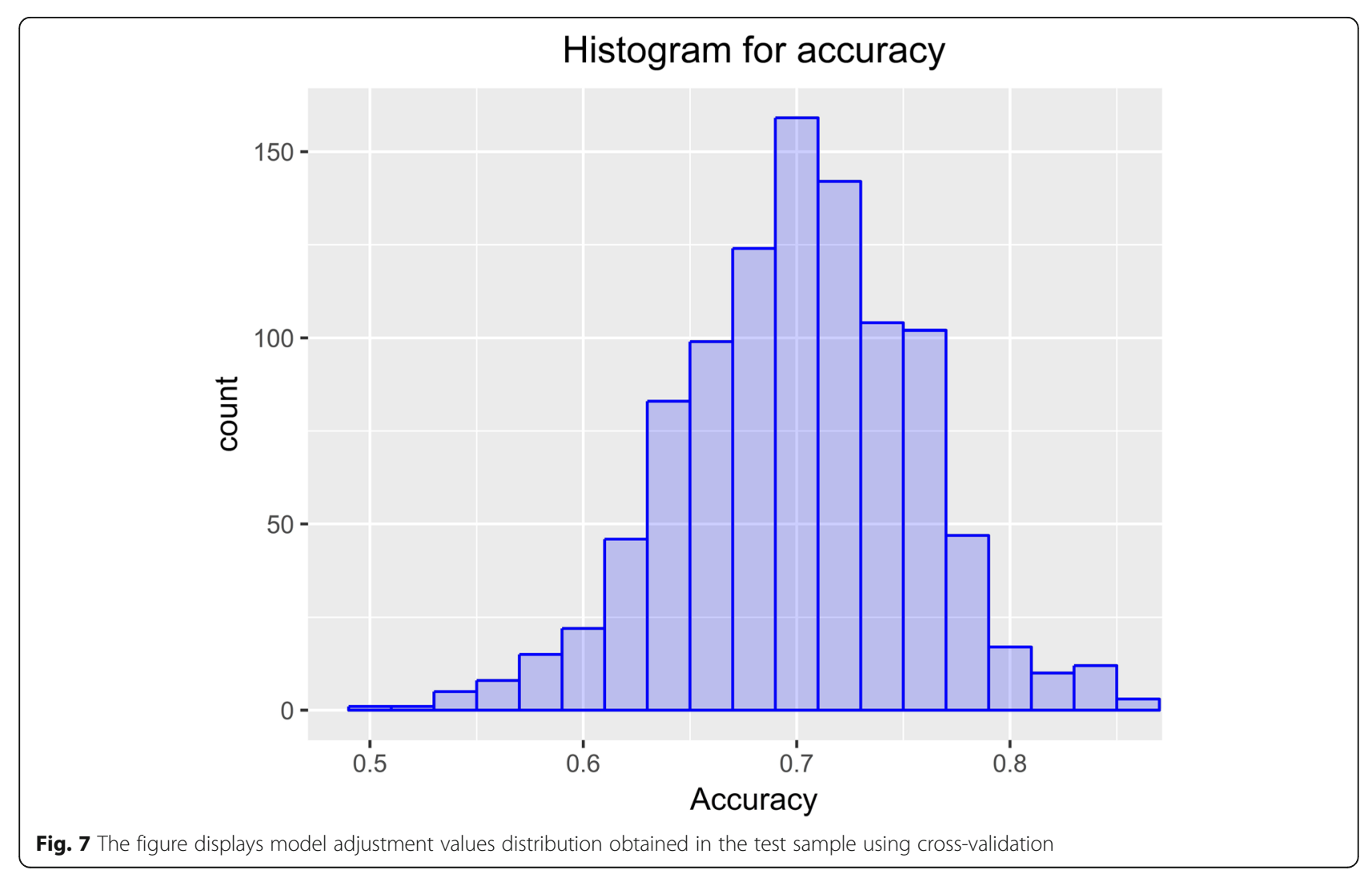




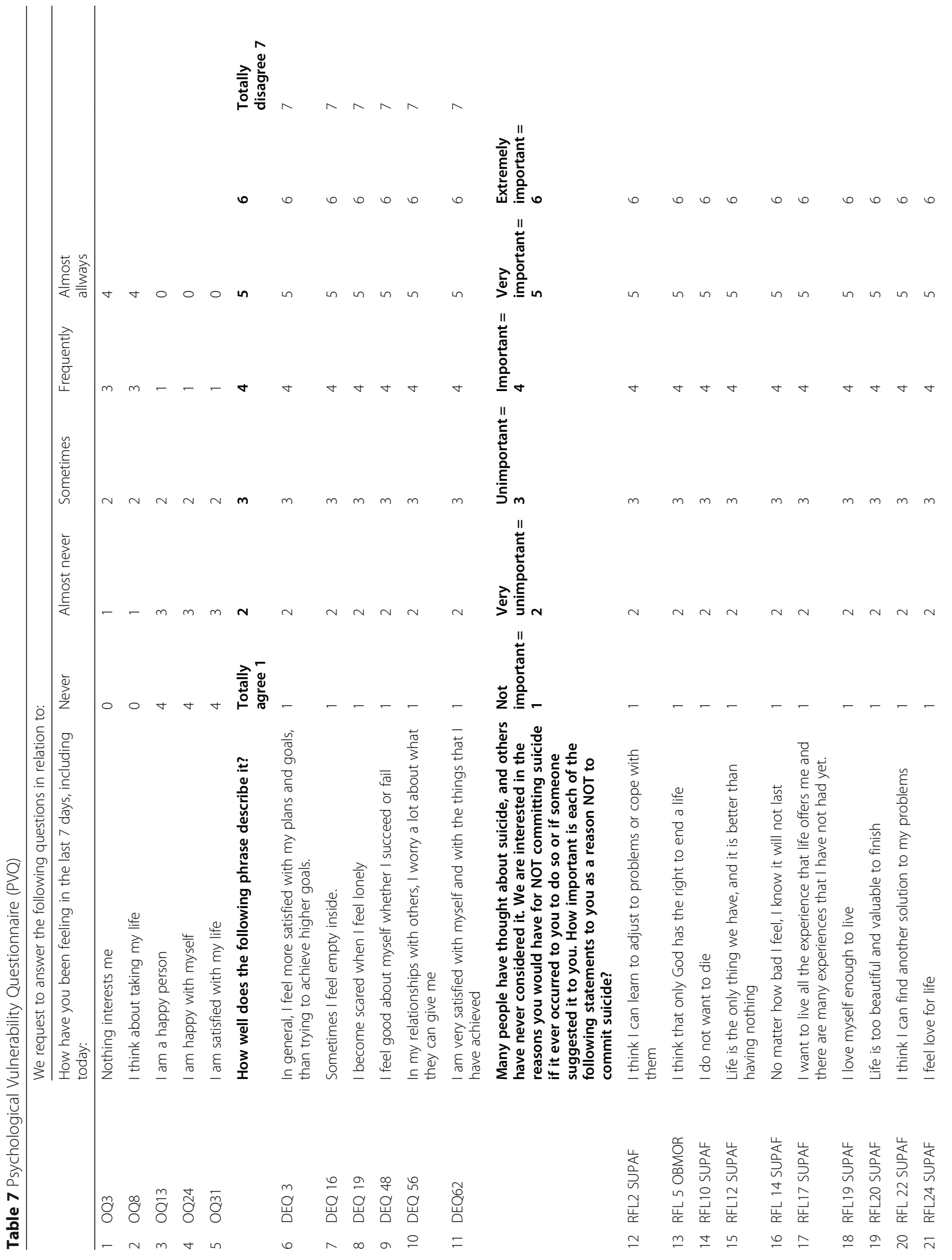




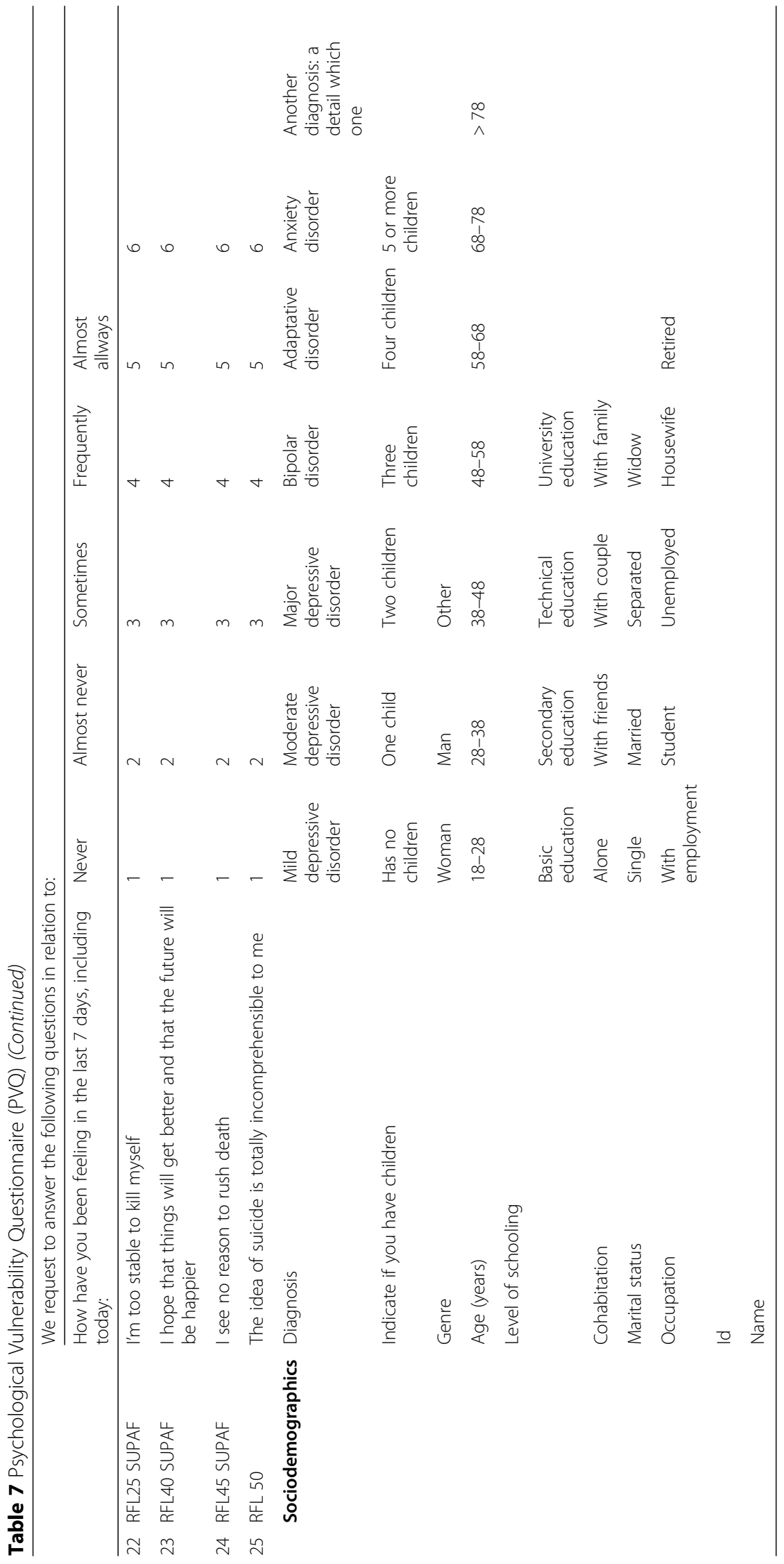


following: feeling aligned with one's own plans and goals, sometimes feeling empty inside, feeling afraid when alone, feeling good about oneself whether one succeeds or fails, being concerned about relationships with others and what other can provide, and feeling satisfied with oneself and what one has achieved. These attributes also included ascribing more or less importance to reasons for attempting suicide, such as thinking that one can adapt to problems or that only God has the right to end a life; not wanting to die; thinking that life is all that we have and is better than nothing; knowing that feeling bad will not last forever, no matter how bad it becomes; wanting to experience everything that life has to offer; loving oneself enough to stay alive; considering life to be too beautiful and precious to bring to an end; thinking that a solution can be found to any problem; feeling love for life; feeling too stable to kill oneself; hoping that things will get better and that the future will be happier; seeing no reason to hurry death; and considering the idea of suicide as totally incomprehensible. According to their joint probabilities, these variables supported the formation of a state of vulnerability, which were highly changeable and could be modified, such as feeling satisfied/ dissatisfied with oneself and with life, being interested in something, having thoughts about ending one's life, feeling like a happy person, and feeling content with oneself and with life. Details of these variables can be seen in the Psychological Vulnerability Questionnaire shown in Table 7.

The use of this instrument provided specific recommendations for the evaluator, such as in the following example: for one participant, the answers provided placed the participant in the risk of suicidal behavior group with a probability of approximately $60 \%$. In the presence of suicidal ideation, feelings of emptiness and dissatisfaction with oneself should be given special attention, and the expectations the patient has regarding interpersonal relationships and the presence of hopelessness should be evaluated.

\section{Discussion}

The general purpose of our work was to identify more accurately which clinical aspects of mood and anxiety disorders are most likely to be seen in a patient at risk of suicide. This can be considered a clinical study because we sought to establish a tool that recognizes risk based on a select group of variables, which may then be included in psychotherapeutic interventions. We recognize these findings to be part of a broader initiative to explore new methods and work strategies, whose applications and usefulness are just beginning to be known.
In this study, we established conditional dependence relationships between factors (transitory or stable) that were predominant in patients with suicidal ideation or who had recently attempted suicide. By systematizing variables with the Bayesian network method, we could visualize an image that showed directed graphs with the nodes and edges representing random variables in conditional dependency relationships or the correlations among them, which emerged within a time context. The relative values of each variable were defined by the algorithm that could assess whether a patient was or was not in a state of vulnerability. This method of organizing and selecting rich data could assist in recognizing relevant aspects of $\mathrm{SB}$, which could be focused on in early interventions.

Our results could be compared to those yielded by traditional statistical methods with different metrics. However, the purpose of this study was not to make comparisons with other methods. Instead, we aimed to gain greater knowledge on how data mining can be used to understand suicidal behavior [8].

The results from analyzing Bayesian networks are considered to be measures used to adjust training data. Further studies to validate the instrument are necessary, which could allow us to obtain accuracy metrics of its predictive power in terms of precision, specificity, and sensitivity. New evaluations from hospitalized and outpatient participants should be considered for future studies validating the model.

The sequence of data mining analyses (SVM and DT) provided a fine-grained view of the data, which illuminated interrelationships that could configure vulnerability states. The use of the $\mathrm{BN}$ technique assisted in identifying individual treatment indications given the following conditional dependence relationships between attributes: having an impact on vulnerability, coexisting and being relatively stable over time, and being part of a state of psychological vulnerability. These conditional dependence relationships can be considered protective and risk factors, depending on the case at hand, and can be related to degrees of satisfaction with oneself, with others, and with life as well as the relative to values assigned to reasons for staying alive.

Our sample included patients with mood and anxiety symptomatology who were willing to participate in this study. We decided to restrict our sample to the most frequent group of patients in clinical practice. With the aim of extending its use to other diagnostic groups, our instrument should be tested on samples with greater diagnostic variety. The results reported here can contribute to better recognition of a mental state that might precede SB. Similar to targeting obesity, high blood pressure, and a sedentary lifestyle, which might decrease the risk of cardiovascular disorders, our study intended to 
identify factors that could be focused on in early interventions.

The items in the proposed instrument refer to patients' feelings toward themselves, life in general, and reasons for living, making the instrument suitable for use in a range of contexts aside from mental health institutions, such as educational environments or policing. With the use of this psychological evaluation questionnaire, it was possible to create a tool to assess general states of vulnerability and identify individuals who may be at risk of SB and who need to be directed to a specialist for further clinical assessment.

In addition, this instrument has a significant advantage over specific scales or questionnaires regarding suicidal ideation or behavior since it provides suggestions of areas for the patient to work on during psychotherapy in terms of the patient's psychologically strong and fragile aspects. Likewise, this model provides an advantage over traditional instruments, as traditional instruments may have adverse effects when used by poorly trained psychologists or psychiatrists (Arensman personal communication September 10th, 2017 NASP). Our work illuminated the use of traditional variables in a different way. As international research has suggested, this different approach could be considered the start of a new paradigm. Our overall aim was to contribute to public health with a new tool that aims at recognizing specific profiles of patients who might be in states of vulnerability. Interventions based on this tool could be adapted to specific characteristics found in each patient. This is a model that might be welcomed by those who support personalized interventions.

The process of evaluation and first intervention with this type of tool should broaden patients' perspectives by allowing them to explain the subjective logic behind their suicidal behavior and identify what affects them and what helps them in times of suicidal crisis. This type of tool could enable interventions to focus upon configurations of particular factors that can be enhanced or diminished in psychotherapy. Psychotherapeutic work could then focus on promoting emerging aspects such as current coping abilities, personal stability, the capacity to regulate emotions, feelings of personal competence, and feelings of satisfaction with oneself and with achievements. Such work could also serve to develop skills and areas of interest in life, to strengthen one's reasons to stay alive, and to reinforce support networks.

Likewise, this type of tool could allow patients to deepen their psychological elaborations of their feelings of disability, their capacity for emotional regulation and their dissatisfaction with oneself and with life. Furthermore, it may help in identifying and changing patterns of negative beliefs about oneself and others and mitigating traits of extreme dependence or extreme self-demand to alleviate despair and hopelessness.

Limitations of our findings should not be disregarded. As mentioned previously, our sample only included patients with major depression using DSM IV criteria. The diagnostic criteria for depression and anxiety in the DSM V contain modifications that we will have to include in the application of the results of our work.

Another limitation of this study is the exclusion of patients who had addictions, eating disorders, psychotic disorders or cognitive disorders. This decision was methodological, with the purpose of controlling the diagnostic variable in the detection of psychological vulnerability. It would be advisable for future research to include these pathologies in the study of psychological vulnerability to suicide.

The absence of data from those who decided not to participate and from those who, having initially accepted, later withdrew from the study, is another limitation of these findings.

Age needs to be examined more closely in further studies since our sample included patients above 14, and responses were similar across different age groups. Regarding the relationship between income and suicidal behavior, although there is evidence of an association between the two variables, this association needs to be explored further ( [20]; Knipe et al., 2015 [21];). The present study did not reveal differences relative to income and suicidal behavior since the sample included a relatively heterogeneous level of income. Finally, information that was not provided by individuals who chose not to participate in the study may have changed the results if it had been included.

\section{Conclusion}

As a recent review of the use of DM and AI to study SB showed, our work is consistent with the experience of many authors who supported the use of these techniques to study SB [8]. However, our interest in more precisely identifying the major factors associated with the mental state that precedes SB and their configuration is a new approach. This is an important methodological difference from the work cited in the mentioned review, as we have discussed in this manuscript. The usefulness of this new approach will need to be evaluated in subsequent studies.

While it is not possible to predict suicide risk today, we can more accurately explore the state of mind that patients experience closest to the time of suicidal behavior". The usefulness of our results must be evaluated prospectively. To do so, we must follow the evolution of behavior based on the variables that show these results. 
We are already doing this in a sample of emergency services patients. We are currently following a sample of patients using several clinical instruments to evaluate the usefulness of our tool.

Our findings allow for the proposal of new goals for further studies. First, we need to evaluate the usefulness of this model in samples with broader diagnostic profiles (since these findings are applicable only to patients with mood disorders). We also believe that it is convenient to classify risk groups according to age and/or pathology to study whether the risk profile of SB has differences in these groups with respect to others. All of these steps are taken with the purpose of recognizing risk patterns that can be highly specific and personal.

\section{Acknowledgments}

Not applicable.

\section{Authors' contributions}

All authors have read and approved the final manuscript. JB, SM \& AG have made substantial contributions to the conception, design of the work, the acquisition, analysis, interpretation of data. They have drafted the work and substantively revised it. OE, RF, MS, CM, CN, \& AT have made substantial contributions to the design of the work, acquisition of data, and they have drafted the work. All authors have agreed with both, be personally accountable for the author's own contributions and to ensure that questions related to the accuracy or integrity of any part of the work, even ones in which the author was not personally involved, are appropriately investigated, resolved, and the resolution documented in the literature.

\section{Funding}

This study was funded by grant $N^{\circ} 11121390$ from the National Fund for Scientific and Technological Development (FONDECYT) for research initiation. It was also supported by grant N IS130005 from the Fund for Innovation and Competitiveness (FIC) of the Chilean Ministry of Economy, Development, and Tourism through the Millennium Science Initiative Funding. This study was sponsored by the Department of Psychiatry of the School of Medicine at the Pontifical Catholic University of Chile. We also thank the Red de Salud UC - Christus: San Carlos de Apoquindo Clinic, the San Joaquín Mental Health Center, Servicio de Salud Metropolitano Sur Oriente (Southeastern Metropolitan Health Service), and Complejo Asistencial Hospital Doctor Sótero del Río (Doctor Sotero del Río Hospital Complex).

\section{Availability of data and materials}

The dataset of this research is deposited in a publicly available repository in an Excel spreadsheet. Synapse ID: syn20048270 DOl:https://doi.org/10.7303/ syn20048270.1. Conditions for use: Controlled Use.

\section{Ethics approval and consent to participate}

The protocol was approved by the institutional ethics committees of the School of Medicine of the Pontificia Universidad Católica de Chile and the Sótero del Río Hospital.

This research had been performed in accordance with the Declaration of Helsinki. The participants were guided through the questionnaires form by specially trained evaluators. They consented by writing to participate in this research. If participants were minors, the consent form was signed by their guardian or caregiver.

\section{Consent for publication}

Not applicable.

\section{Competing interests}

The authors declare that they have no competing interests.

\section{Author details}

${ }^{1}$ Psychiatry Department, School of Medicine, Pontificia Universidad Católica de Chile, La Reconquista 498, Las Condes, Santiago, Chile. ${ }^{2}$ Millennium
Institute for Research in Depression and Personality MIDAP, Santiago, Chile. ${ }^{3}$ Independent mathematical engineer, Santiago, Chile. ${ }^{4}$ School of Nursing, San Sebastian University, Santiago, Chile. ${ }^{5}$ School of Psychology, Diego Portales University, Santiago, Chile.

Received: 26 June 2019 Accepted: 6 March 2020

Published online: 30 March 2020

\section{References}

1. American Psychiatric Association. Diagnostic and statistical manual of mental disorders, vol. 25. 5th ed edA. P. P. Incorporated, Ed: American Psychiatric Publishing, Inc; 2013. https://doi.org/10.1176/appi.books. 9780890425596.744053.

2. Antonucci A, Zaffalon M. Probabilistic graphical models. In: Introduction to imprecise probabilities. Chichester: Wiley; 2014. p. 207-29.

3. Bae SM. The prediction model of suicidal thoughts in Korean adults using decision tree analysis: a nationwide cross-sectional study. PLoS One. 2019. 14(10):1-10. https://doi.org/10.1371/journal.pone.0223220.

4. Baader T, Richter P, Mundt C. Suicidios de pacientes psiquiátricos hospitalizados y sus factores de riesgo: un estudio Caso control. Revista chilena de neuro-psiquiatría. 2004;42(4):293-316. https://doi.org/10.4067/ S0717-92272004000400006.

5. Barros J, Morales S, Echávarri O, García A, Ortega J, Asahi T, et al. Suicide detection in Chile: proposing a predictive model for suicide risk in a clinical sample of patients with mood disorders. Rev Bras Psiquiatr. 2017;39(1):1-11. https://doi.org/10.1590/1516-4446-2015-1877.

6. Boser BE, Guyon IM, Vapnik VN. A training algorithm for optimal margin classifiers. In: Proceedings of the 5th annual acm workshop on computational learning theory; 1992. p. 144-52.

7. Bramer M. Principles of data mining. London: Springer; 2007.

8. Burke TA, Ammerman BA, Jacobucci R. The use of machine learning in the study of suicidal and non-suicidal self-injurious thoughts and behaviors: a systematic review. J Affect Disord. 2019;15(245):869-84. https://doi.org/10. 1016/j.jad.2018.11.073.

9. Chung DT, Ryan CJ, Hadzi-Pavlovic D, Singh SP, Stanton C, Large MM. Suicide rates after discharge from psychiatric facilities. JAMA Psychiatry. 2017;74(7):694-702. https://doi.org/10.1001/jamapsychiatry.2017.1044.

10. De Berardis D, Fornaro M, Orsolini L, Valchera A, Carano A, Vellante F, et al. Alexithymia and suicide risk in psychiatric disorders: a mini-review. Frontiers in Psychiatry. 2017;8(148):1-6. https://doi.org/10.3389/fpsyt.2017.00148.

11. Erlangsen A, Zarit SH, Conwell Y. Hospital-diagnosed dementia and suicide: a longitudinal study using prospective, Nationwide register data. Am J Geriatr Psychiatr. 2008;16(3):220-8. https://doi.org/10.1097/JGP. Ob013e3181602a12.

12. Franklin JC, Ribeiro JD, Fox KR, Bentley KH, Kleiman EM, Huang X, et al. Risk factors for suicidal thoughts and behaviors: a meta-analysis of 50 years of research. Psychol Bull. 2017;143(2):187. https://doi.org/10.1037/bul0000084.

13. Galynker I, Yaseen ZS, Cohen A, Benhamou O, Hawes M, Briggs J. Prediction of suicidal behavior in high risk psychiatric patients using an assessment of acute suicidal state: the suicide crisis inventory. Depress Anxiety. 2017;34(2): 147-58. https://doi.org/10.1002/da.22559.

14. Gut A. Probability: a graduate course. 2nd ed. New York: Springer; 2013. ISBN 978-1-4614-4707-8.

15. Hawgood J, De Leo D. Suicide prediction - a shift in paradigm is needed. Crisis. 2016;37(4):251-5. https://doi.org/10.1027/0227-5910/a000440.

16. Hawton K, Casañasi Comabella C, Haw C, Saunders K. Risk factors for suicide in individuals with depression: a systematic review. J Affect Disord. 2013; 147(3):17-28. https://doi.org/10.1016/j.jad.2013.01.004.

17. Herzog DB, Greenwood DN, Dorer DJ, Flores AT, Ekeblad ER, Richards A, et al. Mortality in eating disorders: a descriptive study. Int J Eat Disord. 2000; 28(1):20-6. https://doi.org/10.1002/(SICI)1098-108X(200007)28:1<20::AIDEAT3>3.0.CO;2-X.

18. Lambert MJ, Burlingame GM, Umphress V, Hansen NB, Vermeersch D a, Clouse GC, et al. The reliability and validity of the outcome questionnaire. Clin Psychol Psychother. 1996;3(4):249-58. https://doi.org/10.1002/(SICI)10990879(199612)3:4<249::AID-CPP106>3.0.CO;2-S.

19. Large M, Kaneson M, Myles N, Myles H, Gunaratne P, Ryan C. Meta-analysis of longitudinal cohort studies of suicide risk assessment among psychiatric patients: heterogeneity in results and lack of improvement over time. PLoS One. 2016;11(6):1-17. https://doi.org/10.1371/journal.pone.0156322. 
20. Lemmi V, Bantjes J, Coast E, Channer K, Leone T, McDaid D, et al. Suicide and poverty in low-income and middle-income countries: a systematic review. Lancet Psychiatry. 2016;3(8):774-83. https://doi.org/10.1016/S22150366(16)30066-9.

21. Liu X, Huang Y, Liu Y. Prevalence, distribution, and associated factors of suicide attempts in young adolescents: school-based data from 40 lowincome and middle-income countries. PLoS One. 2018;13(12):1-12. https:// doi.org/10.1371/journal.pone.0207823.

22. Ma J, Batterham PJ, Calear AL, Han J. A systematic review of the predictions of the interpersonal-psychological theory of suicidal behaviour. Clin Psychol Rev. 2016:46(1):34-45.

23. Maino MD, Morales S, Echávarri O, Barros J, García A, Moya C, et al. Suicide risk configuration system in a clustered clinical sample: a generalized linear model obtained through the LASSO technique. Braz J Psychiatry. 2018;41(2): 112-21. https://doi.org/10.1590/1516-4446-2017-0028.

24. Morales S, Armijo I, Moya C, Echávarri O, Barros J, Varela C, et al. Percepción de cuidados parentales tempranos en consultantes a salud mental con intento e ideación suicida. Avances En Psicología Latinoamericana. 2014; 32(3):403-17. https://doi.org/10.12804/apl32.03.2014.06.

25. Morales S, Barros J, Echávarri O, García F, Osses A, Moya C, et al. Acute mental discomfort associated with suicide behavior in a clinical sample of patients with affective disorders: ascertaining critical variables using artificial intelligence tools. Front Psychiatry. 2017;8:1-16. https://doi.org/10.3389/fpsyt.2017.00007.

26. Morales S, Echávarri O, Barros J, Maino M, Armijo I, Fischman R, et al. Intento e Ideación Suicida en Consultantes a Salud mental: Estilos Depresivos, Malestar interpersonal y Satisfacción familiar. Psykhe. 2016;26(1):1-14. https://doi.org/10.7764/psykhe.26.1.939.

27. Nagarajan RN, Scutari M, Lëbre S. Bayesian networks in R: with applications in systems biology. New York: Springer; 2013. https://doi.org/10.1007/978-14614-64463.

28. Nowicki E, Smutnicki C. A fast tabu search algorithm for the permutation flow-shop problem. Eur J Oper Res. 1996;91(1):160-75. https://doi.org/10. 1016/0377-2217(95)00037-2.

29. OCDE. Health at a glance 2015: OECD indicators. Paris: OECD Publishing; 2015. https://doi.org/10.1787/health_glance-2015-en.

30. Oh J, Yun $\mathrm{K}, \mathrm{H}$ wang J-H, Chae J-H. Classification of suicide attempts through a machine learning algorithm based on multiple systemic psychiatric scales. Front Psychiatry. 2017;8:1-8. https://doi.org/10.3389/fpsyt.2017.00192.

31. Core Team R. R: a language and environment for statistical computing. Vienna; 2019. Retrieved from https://www.R-project.org/.

32. Shlens J. A tutorial on principal component analysis; 2014. Retrieved from https://arxiv.org/pdf/1404.1100v1.pdf.

33. Sucar L, Tonantzintla M. Redes Bayesianas. In Aprendizaje Automático: conceptos básicos y avanzados; 2006. p. 77-100. Retrieved from http://wwwusers.cs.umn.edu/ andre/arquivos/pdfs/bayesianas.pdf.

34. Taylor T, Morales S, Zuloaga F, Echávarri O, Barros J. Lo que nos dicen los padres: Perspectivas de los padres de pacientes hospitalizados por ideación o intento suicida. Revista Argentina de Clínica Psicológica. 2012;21(3):271-80 https://www.redalyc.org/pdf/2819/281929021008.pdf.

35. Tucker RP, Michaels MS, Rogers ML, Wingate LRR, Joiner TE. Construct validity of a proposed new diagnostic entity: acute suicidal affective disturbance (ASAD). J Affect Disord. 2016;189:365-78. https://doi.org/10. 1016/j.jad.2015.07.049.

36. Verrocchio MC, Carrozzino D, Marchetti D, Andreasson K, Fulcheri M, Bech P. Mental pain and suicide: a systematic review of the literature. Front Psychiatry. 2016;7:1-17. https://doi.org/10.3389/fpsyt.2016.00108.

37. Von Bergen A, de la Parra G. OQ-45.2 Cuestionario Para evaluación de resultados y evolución en psicoterapia: Adaptación, validación e indicaciones Para su aplicación e interpretación. Terapia Psicológica. 2002; 20(2):161-76 https://pesquisa.bvsalud.org/portal/resource/pt/lil-389263.

38. Ribeiro JD, Franklin JC, Fox KR, Bentley KH, Kleiman EM, Chang BP, Nock MK. Self-injurious thoughts and behaviors as risk factors for future suicide ideation, attempts, and death: a meta-analysis of longitudinal studies. Psychol Med. 2016:46(2). https://doi.org/10.1017/S0033291715001804. http://www.bnlearn.com/documentation/man/structure.learning.htm.

39. Walsh CG, Ribeiro JD, Franklin JC. Predicting risk of suicide attempts over time through machine learning. Clin Psychol Sci. 2017;5(3):457-69. https:// doi.org/10.1177/2167702617691560.

40. Walsh G, Sara G, Ryan CJ, Large M. Meta-analysis of suicide rates among psychiatric in-patients. Acta Psychiatr Scand. 2015;131(3). https://doi.org/10. 1111/acps. 12383.
41. White J. What can critical suicidology do? Death Studies. 2017;41(8):472-80. https://doi.org/10.1080/07481187.2017.1332901.

42. World Health Organization-WHO. Informe mundial sobre la violencia y la salud; 2002. Retrieved September 10, 2017 from http://www.who.int/ violence_injury_prevention/violence/world_report/es/.

43. World Health Organization (WHO). WHO mental health atlas 2014. Geneva: WHO; 2014. Retrieved from http://www.who.int/mental_health/evidence/ atlas/mental_health_atlas_2014/en.

\section{Publisher's Note}

Springer Nature remains neutral with regard to jurisdictional claims in published maps and institutional affiliations.
Ready to submit your research? Choose BMC and benefit from:

- fast, convenient online submission

- thorough peer review by experienced researchers in your field

- rapid publication on acceptance

- support for research data, including large and complex data types

- gold Open Access which fosters wider collaboration and increased citations

- maximum visibility for your research: over $100 \mathrm{M}$ website views per year

At BMC, research is always in progress.

Learn more biomedcentral.com/submissions 